\title{
Are persons with physical disabilities who participate in society healthier and happier? Structural equation modelling of objective participation and subjective well-being
}

\author{
Cretien van Campen · Jurjen Iedema
}

Received: 20 March 2006/ Accepted: 26 October 2006/ Published online: 1 February 2007

(C) Springer Science+Business Media B.V. 2007

\begin{abstract}
In many countries, governments pursue a policy of offering persons with disabilities greater opportunities for participation in society, based on the assumption that this will also improve their subjective well-being. Currently, however, it is not known whether this assumption is valid. In this study we relate the objective participation and the subjective well-being aspects of both disabled and non-disabled persons to an array of social and health-related determinants. Linear structural equation modelling of data of a sample selection of the Dutch population is analysed. The sample size is 5,826 , including 642 respondents with physical disabilities. In terms of objective participation, the persons with disabilities are at a greater disadvantage as regards labour participation than is the case for social and cultural participation. When it comes to subjective well-being, we find that the persons with disabilities are more likely to lag behind in perceived physical health than in mental health and happiness. In a multivariate model relating objective participation to subjective health and happiness, correlations are much weaker than expected. It is striking to find that participation, perceived health and happiness are much less closely related than is often assumed. Their determinants differ widely in nature and strength. The empirical model leads to rejection of the hypothesis that higher participation by the persons with disabilities is associated with higher subjective well-being.
\end{abstract}

C. van Campen $(\bowtie) \cdot$ J. Iedema

Social and Cultural Planning Office, P.O. Box 16164, The Hague 2500 BD, The Netherlands

e-mail: c.van.campen@scp.nl
Keywords Quality of life - Social participation . Perceived health · Happiness · Persons with disabilities $\cdot$ Structural models

\section{Introduction}

The general public image of persons with physical disabilities is that they have a low quality of life (QOL). There is a general consensus that their QOL should be improved and many countries have adopted this view as an official policy, passing laws like the Disability Discrimination Act in order to offer persons with disabilities the same rights to public services as non-disabled citizens. Governments facilitate better access for persons with disabilities to the jobs market, education and transport in order to stimulate the societal participation of this group. The target of policymakers is to normalise the lives of persons with disabilities, i.e., raise the level of their QOL to bring it closer to that of non-disabled persons $[1,2]$. The implicit assumption of this policy is that more participation by persons with disabilities not only improves their standard of living, but also their subjective well-being. But, are persons with physical disabilities who participate in society happier? The objective of this article is to explain differences in subjective well-being with respect to disabilities in activities and participation in the Dutch population.

Who are persons with disabilities and when do they participate in society? The international classification of functioning, disability and health (ICF) identifies three levels of human function: body functions and structures, activities, and participation. The term disability is used to denote a decrement at each level. 
Disability on the level of body is defined by the ICF as a problem in bodily functioning, on the level of activities as a limitation in executing activities like walking or personal care and on the level of participation as a restriction an individual may experience in involvement in life situations, like labour, going to museums, going on holidays and meeting friends [3, 4]. The disablement process theory links the elements in a linear order: impairments in bodily functions lead to limitations in activities and lead in turn to restrictions in objective participation [4]. In this article, we define persons with disabilities as the group of people with moderate or severe limitations in physical activities. We define 'objective participation' as the observable involvement in society, e.g., as can be observed in labour participation statistics.

Subjective well-being is not included in the ICF and disablement process theory. Post et al. [5] studied the position of subjective well-being and other outcome measures in the ICIDH framework (the forerunner of ICF) for rehabilitation research. They suggested to distinguish between subjective and objective aspects of quality of life and placing the subjective well-being as an outcome of the ICIDH model. In accordance, we place subjective well-being at the end of the line in the disablement process.

Within the wide range of indicators of subjective well-being we select the ones most often used: perceived health and happiness. 'Perceived health' is defined as a person's appraisal of his or her physical, mental and social functioning in daily life (also known as health-related quality of life or HRQOL) [3, 6-8], and 'happiness' is defined as someone's satisfaction with life in general [9]. In line with the ICF, the disablement process theory and the aforementioned study on subjective well-being, we model differences in perceived health and happiness as outcomes of the disablement process (see Fig. 1).

\section{Objective participation and subjective well-being}

Little research has been carried out into quantitative differences in participation and subjective well-being between people with and without physical disabilities. People with long-term physical disabilities are at a disadvantage compared to people without disabilities in all kinds of areas of society, such as employment, income, education, cultural participation and leisure activity $[1,2]$. The severity of the physical limitation and socio-economic characteristics are found to be the main determinants of their reduced social participation.

Differences in perceived mental health between people with and without mobility restrictions can be explained almost entirely by socio-economic, health, housing and time use characteristics, as can roughly a third of the differences in perceived physical health between the two groups [10]. Differences in satisfaction with life in general between people with and without spinal injury are explained by socio-economic characteristics in another study too [11]. In addition to these characteristics, the influence of incapacitating disorders of the locomotory apparatus (in particular back problems and joint wear) on perceived health has been pointed out [12]. In general, persons' are socioemotional positions (regular partner, friends) are more important than their socio-economic position in determining their happiness [13].

Many studies focus on groups with specific disorders, without making comparisons with the population as a whole. In studies involving people with physical disabilities, the determinants of subjective well-being referred to above have been found [14, 15]. Strikingly, disorders and physical limitations explain the differences in the social participation of persons with disabilities, but offer little or no explanation for the differences found in perceived health and general satisfaction with life [16-18]. The latter criterion shows a reasonably strong correlation with opinions about happiness and is also used as an indicator for this [13].

A more general discussion has taken place on the relationship between objective participation and subjective well-being in national populations, and useful information can be drawn from this [7, 19]. In general, there is a correlation between social participation and subjective well-being, though it is not a strong one [8]. Several studies have found relatively strong correlations between subjective participation in employment and satisfaction with life in general, $[20,21]$ between perceived health and socio-cultural participation (associational life, voluntary work, social isolation), [22] and between social exclusion and mental well-being [23]. However, no distinction is drawn in these studies between people with and without disabilities. As differ-

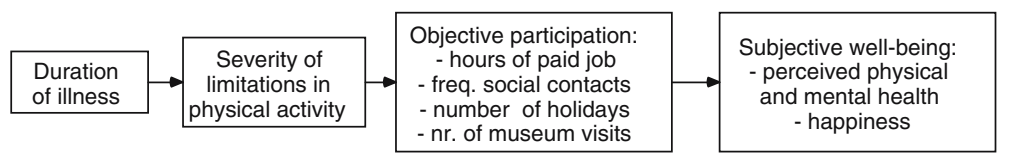

Fig. 1 First model of quality of life. Note: The fit and the explained variance of the model are shown in Table 2 
ent criteria are used in studies, there is accordingly a need for clear, well-defined indicators, which among other things enable a sharper distinction to be drawn between social environment (participation opportunities), social situation (objective participation), perception of this (subjective participation) and subjective wellbeing [9].

\section{Method}

\section{Sample}

Use was made for this study of the Dutch permanent life situation survey (POLS)-Basic Module plus the Module on Health and Employment, 2001 and 2002 editions, published by Statistics Netherlands (CBS). This survey of in-person interviews and additional written questionnaires) provides a national representative dataset on persons from the non-institutional population aged 12 years and over in The Netherlands. Data are collected from new samples every year. The response was $62 \%$ in 2001 and $61 \%$ in 2002. Therefore the samples have been weighed to the population. In the 2001 edition of POLS, 5,826 cases were usable for analysis; in POLS2002 there were 5,677 . The dropout rate was $4.1 \%$ and $4.0 \%$, respectively, and was the result of missing values on the scales for physical limitations and perceived health.

The sample was drawn at random from persons in the Dutch population, which is described by Statistics Netherlands (www.cbs.nl). The socio-demographic characteristics of the 2001 sample are shown in Table 1. Persons with moderate or severe physical disabilities differ in a number of respects from other citizens. As earlier research has shown, the former group contains more women, more older persons, more people with a low education level and a low income [2].

\section{Measurement instruments}

The elements of the first model of 'impairments in bodily functions'-'limitations in activities'-'restrictions in participation'-(low) 'subjective well-being' were operationalized with the variables available in the dataset. Impairments in bodily functions was assessed with a rather general indicator of duration of illness since population research has shown that chronic illnesses have a main effect on disability, participation and subjective well-being [2, 12, 24]. The indicator of duration of illness consist of three categories: none, short, and long.
Table 1 Socio-demographic characteristics of the sample of the Dutch non-institutionalized population of 12 years and older with regard to the level of physical limitation, 2001 (percentages)

\begin{tabular}{lccccc}
\hline & $\begin{array}{l}\text { No } \\
\text { physical } \\
\text { limitation }\end{array}$ & $\begin{array}{l}\text { Light } \\
\text { physical } \\
\text { limitation }\end{array}$ & $\begin{array}{l}\text { Moderate } \\
\text { physical } \\
\text { limitation }\end{array}$ & $\begin{array}{l}\text { Serious } \\
\text { physical } \\
\text { limitation }\end{array}$ & $\begin{array}{l}\text { Total } \\
\text { popu- } \\
\text { lation }\end{array}$ \\
\hline $\begin{array}{l}\text { Female } \\
65 \text { years }\end{array}$ & 49 & 54 & 54 & 64 & 51 \\
$\quad \begin{array}{l}\text { and } \\
\text { older }\end{array}$ & 7 & 22 & 36 & 48 & 14 \\
$\begin{array}{c}\text { Low } \\
\text { education }\end{array}$ & 38 & 50 & 52 & 73 & 43 \\
$\begin{array}{c}\text { Lowest } \\
\text { income } \\
\text { decile }\end{array}$ & 5 & 9 & 16 & 19 & 7 \\
$n \quad$ & 3927 & 1257 & 281 & 361 & 5826 \\
\hline
\end{tabular}

Statistics Netherlands (POLS'01), SCP processing

\section{Severity of physical limitations}

The severity of the physical limitations in activities was measured using the physical disabilities indicator developed by the Organisation for Economic Cooperation and Development (OECD) (www.oecd.org). This indicator is based on seven questions relating to hearing impairment, visual impairment and locomotory limitations (being able to carry an object weighing $5 \mathrm{~kg}$, for example a full shopping bag, for $10 \mathrm{~m}$, being able to bend and pick something up from the floor from a standing position, and being able to walk a distance of $400 \mathrm{~m}$ without stopping, if necessary with a walking stick). A person has severe limitations if he or she answers one or more of the questions by saying that they cannot do it, or only with the help of others; they have moderately limitations if they answer one or more of the questions with 'with great difficulty' (and did not answer any other questions with 'cannot do it'); have slightly limitations if they answer at least one question with 'with some difficulty'. The reliability (Cronbach's alpha $=0.79$ ) and validity of the scale are good [25].

\section{Objective participation}

The available database contains no instrument to measure participation in society. Therefore we selected a number of indicators for objective participation, i.e., social participation ('How often do you have contact with friends and acquaintances or really close friends?'), cultural participation ('How often have you visited a museum in the Netherlands in the last 12 months?'), leisure participation ('How often have you been on holiday in the last 12 months?'), and la- 
bour market participation ('How many hours in total do you work in a normal working week, not including unpaid hours?').

\section{Subjective well-being}

Subjective well-being was measured using two indicators: perceived health and happiness. The most commonly used instrument for measuring perceived health or health-related quality of life is the Short Form 36 (SF-36) and the (even more) abridged form, the SF-12 [6, 24, 26, 27]. This instrument is also used in rehabilitation studies [28]. It has been extensively tested on a variety of research populations in more than 50 countries. The SF-12 comprises 12 questions on perceived health. Based on the responses, two main measures are calculated: a Physical Component Summary and a Mental Component Summary, for which we will use the terms 'perceived physical health' and 'perceived mental health' here. In addition, the scores were calculated on eight more specific dimensions of perceived health: physical functioning, physical role limitations, bodily pain, general perceived health, vitality, social functioning, emotional role limitations and mental health [6]. Ware et al. standardised the SF-12 measures for the population of the United States. The average is slightly higher in the Dutch population. Based on the national sample used in the POLS2001 survey, the measures were standardised for the Dutch population, with an average of 0 and a standard deviation of 10 . The reliability (Cronbach's alphas of 0.85 ) and validity of the measures proofed to be good in this and other populations $[6,18]$.

The literature reports several difficulties in measuring the perceived physical health of people with physical disabilities using the SF-36 and SF-12 [14, 29, 30]. The two items on physical functioning deal with activities that people with disabilities are by definition unable or barely able to perform (i.e., moving a table, climbing several flights of stairs). The OECD indicator and the SF-12 both contain questions on the ability to walk upstairs and carry out a demanding task, such as lifting a heavy object. It was therefore decided to calculate an adjusted measure for physical well-being, excluding these questions [30, 31]. The other option, adapting the formulation of the questions [14] was not possible here, and this choice would in any event have had implications for the reliability and validity of the SF-12 scale [29].

The indicator 'happiness' was measured with the often used question: 'To what extent would you describe yourself as a happy person?' [13]. The following ordinal background variables were also employed: age, sex (dichotomous), education (six levels), and net household income (in deciles). The variables for duration of illness, severity of physical limitations, perceived health, happiness and the participation were ordinal as well.

\section{Analyses}

The questionnaires were studied using variance analysis and linear structural equation models (path analyses) by means of the program AMOS with Maximum Likelihood estimation [32]. With linear structural equation models it is important that the model fits the data well, since otherwise the coefficients may be inaccurate [33]. We report a number of fit measures. The $\chi^{2}$ measures the difference between the sample covariance matrix and the fitted covariance matrix of the model. It should be non-significant. A drawback is that it is sensitive to sample size so that differences of trivial size may lead to a significant $\chi^{2}$. Therefore other fit measures have been developed such as the goodness of fit index (GFI), which should be less sensitive to sample size. The normed fit index (NFI) and the comparative fit index (CFI) measure how much better the model is than a model in which no relationship between variables is specified. The standardised root mean square residual (SRMR) indicates how large the residues are (a residue is the difference between an observed covariance or variance and the fitted covariance or variance in accordance with the model). The root mean square error of approximation (RMSEA) was developed to ensure that models, which provide a reasonable fit in the population do not need to be discarded immediately in large samples. The final two fit measures can be used to compare between models, for both the expected cross-validation index (ECVI) as for the Akaike information criterion (AIC) holds: the lower the better the model.

For the calculation of the scales and indicators, respondents must have completed all questions. Respondents with incomplete responses are generally removed from the data, but this implies a substantial loss of information and can distort the results. Using the Norm program, missing values were imputed for respondents who had completed at least three-quarters of the questions in the SF-12. Norm imputes missing values for variables based on a multivariate normal distribution [34]. The remaining $2.7 \%$ of the sample with more than three missing answers were removed. 


\section{Results}

Differences in participation and subjective well-being

What are the differences in objective participation and subjective well-being between persons with physical disabilities and persons without disabilities? Table 2 gives a brief summary of the size of the differences in objective participation on the indicators selected for the model. The shortfall in labour participation is large, as is known from several publications $[1,2]$. Three-quarters of people with physical disabilities are not employed. The more serious the physical limitation, the fewer contacts those concerned have with friends. The number of holidays per year reduces drastically in persons with more serious limitations; almost half of those with serious physical limitations do not go on holiday. They also visit museums less often, though the differences here are less marked than for going on holiday.

What are the quantitative differences in subjective well-being for perceived physical and mental health (general plus a subdomains) and happiness? Figure 2 shows that perceived physical and mental health as well as happiness decline as the severity of the physical limitations increases. However, perceived physical health declines more quickly than perceived mental health. The social functioning of people with physical limitations is lowest among the indicators of perceived mental health. This is in line with earlier findings that people with physical limitations lead a socially deprived life [2].
The average difference in perceived physical health between people with severe limitations in physical activities and people without physical limitations is 15 points (or one and a half times the standard deviation). The average difference in perceived mental health and happiness between these two groups is 6 points ( 0.6 of the standard deviation).

Empirical model of activities, participation and subjective well-being

First, we tested the minimal model that subjective wellbeing is predicted by the chain of bodily functioning $\rightarrow$ limitations in activities $\rightarrow$ participation. Testing this model (shown in stylised form in Fig. 1) on the dataset from POLS2001 produced a disappointing result. The fit of the model was poor (see Table 3) for the SRMR, probably some paths have not been included that would improve the model significantly. The RMSEA larger than 0.10 indicates a bad fit. Finally, the explained variance of the outcome variables was low.

We then looked for a model with better fit to the data. First we adapted the relationships between the elements of the model on the basis of modification indices provided by AMOS (this shows the improvement in model fit when adding a path or a covariance). This resulted in a repositioning of the indicators for subjective well-being in the model. The subjective indicators 'perceived health' and 'happiness' were modelled in parallel-rather than in series-to the indicators for objective participation. After these modifications, the fit of the model im-
Table 2 Indicators of social participation in the Dutch non-institutionalized population of 12 years and older with regard to the level of physical limitation, 2001 (percentages)

Source: Statistics Netherlands (POLS'01), SCP processing

\begin{tabular}{lccccc}
\hline & $\begin{array}{l}\text { No } \\
\text { physical } \\
\text { limitation }\end{array}$ & $\begin{array}{l}\text { Light } \\
\text { physical } \\
\text { limitation }\end{array}$ & $\begin{array}{l}\text { Moderate } \\
\text { physical } \\
\text { limitation }\end{array}$ & $\begin{array}{l}\text { Serious } \\
\text { physical } \\
\text { limitation }\end{array}$ & $\begin{array}{l}\text { Total } \\
\text { population }\end{array}$ \\
\hline Paid job hours per week & & & & & \\
None & 28 & 47 & 62 & 77 & 37 \\
Less than 12 h/week & 8 & 6 & 3 & 3 & 7 \\
13-30 h/week & 15 & 14 & 10 & 5 & 14 \\
31 h/week or more & 49 & 33 & 25 & 15 & 43 \\
Number of social contacts with friends & & & & \\
Less than once per month & 3 & 5 & 8 & 12 & 4 \\
Once or twice per month & 16 & 18 & 22 & 19 & 79 \\
Weekly & 81 & 78 & 71 & 69 & 21 \\
Number of holidays per year & 17 & 25 & 35 & 48 & 34 \\
None & 34 & 35 & 33 & 26 & 45 \\
Once & 49 & 41 & 31 & 25 & 63 \\
More than once & & & & & 13 \\
Museum visits per year & 61 & 62 & 73 & 79 & 14 \\
Less than once per year & 14 & 13 & 8 & 9 & 10 \\
Once per year & 15 & 14 & 10 & 7 & 5826 \\
Twice or thrice per year & 10 & 10 & 9 & 5 & \\
Four or more times per year & 3927 & 1257 & 281 & 361 & \\
$n$ & & & & & \\
\hline
\end{tabular}




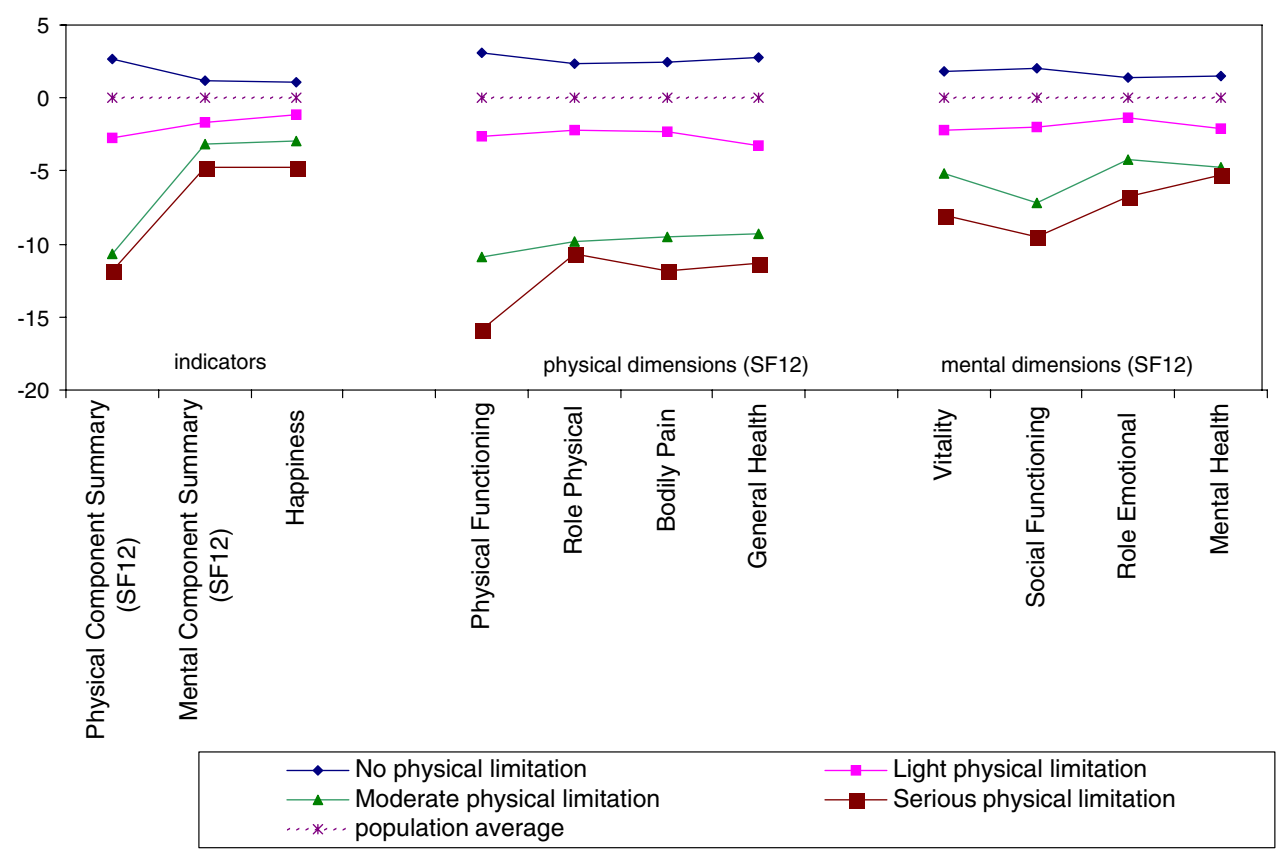

Fig. 2 Perceived physical and mental health and happiness in the Dutch non-institutionalized population of 12 years and older with regard to the level of physical limitation, 2001 (scale values). Source: Statistics Netherlands (POLS'01), SCP processing Note: The scales are standardised to the Dutch population with a mean

proved (e.g., RMSEA $=0.62$ and SRMR $=0.19$ ). Finally, we had to deal with omitted variable bias: important predictors which are left out of the model can lead to biased regression estimates and squared multiple correlations [32]. We added socio-economic of zero and a standard deviation of 10 points. The indicators (on the left) are based on the corrected Physical Component Summary and the regular Mental Component Summary scores of the Short Form 12 [6]

variables to the model. There is a vast literature on the effects of socio-economic characteristics on perceived health $[35,36]$. This step resulted in a model with a good fit. Figure 3 presents a stylised representation of this second model.

Table 3 Comparisons of fit and explained variance $\left(R^{2}\right)$ of the two models of quality of life in the Dutch non-institutionalized population of 12 years and older

$\begin{array}{lllll}\begin{array}{l}\text { Model 1 } \\ \text { (POLS2001) }\end{array} & \text { Model 2 } & \text { Model 2 } & \text { Model 2 age } & \text { Criterium } \\ \text { for good fit }\end{array}$

Fit measures

$\chi^{2}$

df

$p$

Goodness of fit index (GFI)

Normed Fit Index (NFI)

Comparative fit index $(\mathrm{CFI})$

Standardized root mean square residual (SRMR)

Root mean square error of approximation (RMSEA)

Expected cross-validation index (ECVI)

Akaike information criterion (AIC)

$R^{2}$

Physical limitation

Holidays

Museum visits

Paid job hours

Contacts friends

Perceived physical health

Perceived mental health

Happiness
2531.044

10

$<0.05$

0.930

0.978

0.978

0.098

0.208

0.450

2619.044

0.12

0.04

0.01

0.07

0.01

0.06

0.02

0.04

\subsection{2}

17

$<0.05$

0.996

0.999

0.999

0.017

0.038

0.058

335.282

0.25

0.09

0.06

0.28

0.05

0.35

0.07

0.05
177.432

17

$<0.05$

0.995

0.999

0.999

0.018

0.041

0.062

351.432

0.21

0.08

0.04

0.30

0.05

0.25

0.07

0.05
302.006

17

$<0.05$

0.990

0.998

0.998

0.028

0.061

0.106

479.006

0.16

0.08

0.08

0.27

0.04

0.31

0.07

0.04

Source: Statistics Netherlands (POLS’01, ‘02), SCP processing 
Fig. 3 Second model of quality of life. Notes: (1) The fit and the explained variance of the model are shown in Table 3. (2) The standardized path coefficients of the straight lines are shown in Tables 4 and 6 , the standardized correlation coefficients of the curved lines in Tables 5 and 7. (3) Error terms are indicated with the circles with an 'e'

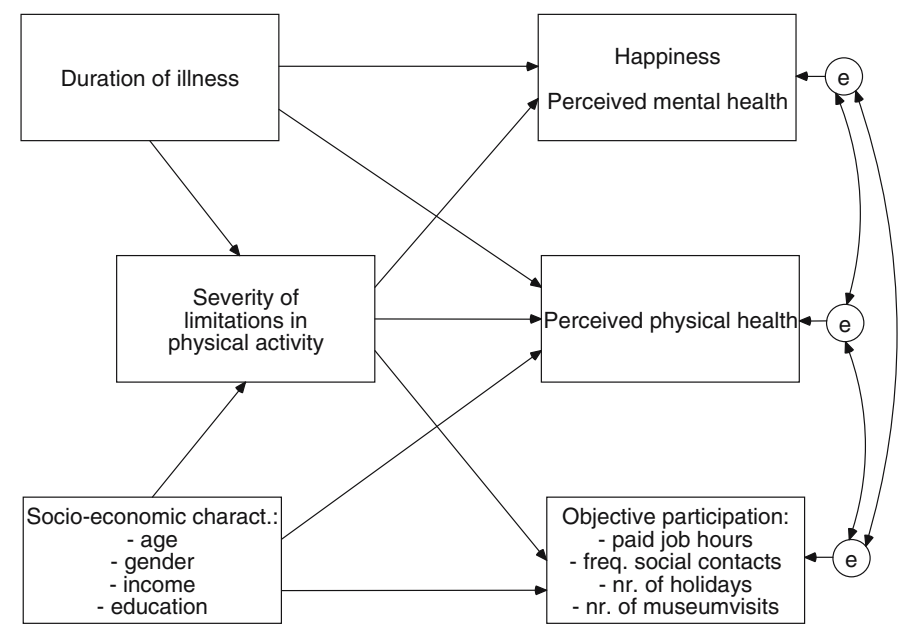

Not only, the fit of the model was good for nearly all fit measures, but also the explained variance increased for all outcome variables (see Table 3). Only the $\chi^{2}$ was significant whereas it should not be, but as said before with the present large sample this is not a reliable fit statistic. The two comparative indexes (ECVI and AIC) show that model 2 fits much better to the data than model 1.

Table 4 contains the standardised path coefficients and Table 5 contains the correlation coefficients of model 2 on the POLS2001 dataset. Table 4 shows that socio-economic characteristics are important explanatory factors for participation, in particular for labour market participation. The differences in perceived physical health can largely be attributed to the severity of the physical limitations in activities and duration of illness. Perceived mental health and happiness are explained to only a small extent by these factors. Overall, this shows that indicators of participation and indicators of subjective well-being differ in their determinants.

Table 5 shows low correlations between indicators of objective participation on the one hand and perceived physical and mental health and happiness on the other hand. Seven out of twelve correlations are significant $(p<0.05)$ and of these seven significant ones no one is higher than $r=0.09$.

As the second model was adjusted using data from POLS2001, we decided to cross-validated it on the data of the following edition of the survey: POLS2002. The results show a similar good fit and high explained variance of the outcome variables (Table 3 ). The little differences between the datasets POLS2001 and POLS2002 may in fact be due to different operationalisations of duration of sickness.

After correction for the variables in model 2, the differences in subjective well-being between people with and without disabilities were found to have reduced. The differences in perceived physical health were still substantial (11 points compared with 15 earlier); the differences in perceived mental health remained unchanged ( 6 points) and the differences in perceived happiness decreased (from 6 to 3 points).

Finally, the second empirical model was tested for specific groups in the population. Since a different correlation may exist between objective participation and subjective well-being in the selected group of people with physical limitations, we tested the model using multiple group analysis. The correlations between the indicators for participation and well-being for the groups of people with and without physical limitations did not differ from each other however $\left(\chi_{\text {difference }}^{2}(21)=11.04, p>0.96\right)$.

Since few people aged 65 years and over perform paid work, a test was also carried out on the potential labour population. Table 6 shows the standardized path coefficients of model 2 in the non-institutionalized population of $18-65$ years. The coefficients of predictors of perceived health and happiness hardly differ from those of the general population model (cf. Table 4). Though we find differences in predictors of objective participation. The severity of limitations in activity has a less negative effect on museum visits and going on holidays. This indicates that persons with disabilities in the age of 18-65 are less restricted in their participation than persons over 65 years. Of course the predictor 'age' plays a different role since the people of 65 years and older were excluded from this dataset. The group of elderly has a relative larger part of persons with disabilities. As a result, the predictor 'age' has a lower effect on severity of the limitations and perceived physical health. Obviously, physical limitations due to high age do play a minor role in this model of the potential labour population. Furthermore, the more 
Table 4 Standardized path coefficients ${ }^{\mathrm{a}}$ of quality of life model 2 in the Dutch non-institutionalized population of 12 years and older $(n=5,826)$

\begin{tabular}{|c|c|c|c|c|c|c|c|c|}
\hline & $\begin{array}{l}\text { Physical } \\
\text { limitation }\end{array}$ & Happiness & $\begin{array}{l}\text { Perceived } \\
\text { mental health }\end{array}$ & $\begin{array}{l}\text { Perceived } \\
\text { physical health }\end{array}$ & Holidays & $\begin{array}{l}\text { Museum } \\
\text { visits }\end{array}$ & $\begin{array}{l}\text { Paid job } \\
\text { hours }\end{array}$ & $\begin{array}{l}\text { Contacts } \\
\text { friends }\end{array}$ \\
\hline Physical limitation & & -0.130 & -0.168 & -0.299 & -0.151 & -0.046 & -0.091 & -0.044 \\
\hline Duration of illness & 0.251 & -0.091 & -0.108 & -0.384 & & & & \\
\hline Gender (female) & 0.038 & & -0.103 & -0.066 & & & -0.200 & \\
\hline Age & 0.331 & & 0.087 & -0.055 & & & -0.266 & -0.194 \\
\hline Net household income & -0.058 & 0.113 & 0.075 & & 0.161 & & 0.147 & \\
\hline Level of education & -0.152 & & -0.040 & & 0.132 & 0.226 & 0.278 & \\
\hline
\end{tabular}

Source: Statistics Netherlands (POLS'01), SCP processing

${ }^{a}$ Nonsignificant $(p>0.05)$ relationships are not entered in the model and remain blank in the table

Table 5 Correlation coefficients ${ }^{\mathrm{a}}$ between error terms of the outcome indicators of quality of life model 2 in the Dutch non-institutionalized population of 12 years and older $(n=5,826)$

Happiness Perceived mental health Perceived physical health Holidays Museum visits Paid job hours

Perceived mental health 0.327

Perceived physical health 0.031

Holidays $\quad 0.065$

Museum visits

Paid job hours

0.051

0.052

$0.046-0.170$

0.036

$-0.136$

0.098

$-0.043$

Source: Statistics Netherlands (POLS'01), SCP processing

${ }^{a}$ Correlations adjusted for model variables. Only significant $(p<0.05)$ coefficients are shown

negative effect of gender on paid job hours is a result of the higher labour participation among men of 65 years and younger. The lower effect of level of education on paid job hours in the potential labour population is explained by the fact that people over the age of 65 have on the average a lower education level and often are not employed anymore.

Table 7 shows the correlations of coefficients between the indicators of quality of life in the non-institutionalized population of 18-65 years. Also in this case the coefficients differ little from the original model, with one exception. Labour participation does have a significant correlation with perceived physical and mental health, even though the correlations are still low $(r<0.07)$.

\section{Discussion}

The first model, which assumed well-being as an outcome of the disablement process of impaired bodily functioning, limited activities and restricted participation, was rejected on basis of the fit criteria. The second model which models subjective well-being and objective participation as parallel outcomes, and includes socioeconomic status, fits the empirical findings good. Above that, the second model explained a higher proportion of the variance in the indicators than the first model.
These results show that a socio-medical model provides a better fit for the empirical reality than a biomedical model. The absence of psychological variables in the database unfortunately meant it was not possible to test the value of a biopsychosocial model. In particular, psychological coping skills could play an important role in explaining differences [37, 38]. However, the effect of coping variables becomes apparent mainly in longitudinal analyses, whereas the database used in this study was cross-sectional.

The model offers new insights with regard to the existing literature. The low correlations between objective participation and subjective well-being appear at first sight to be contra-intuitive and to contradict the literature in this field, which suggests reasonably strong correlations. On closer consideration, two mediating variables are found to play important roles.

The first of these is the severity of the limitations in activities. In the literature, correlations are observed between objective participation and subjective wellbeing without correcting for physical limitations. It is known that socio-economic resources and limitations are influential mediating variables for social participation and subjective well-being. Although the studies referred to generally control for socio-economic resources, they do not do so for physical limitations. In the present study, however, physical limitation is found to play an important background role. 
Table 6 Standardized path coefficients ${ }^{\mathrm{a}}$ of quality of life model 2 in the Dutch non-institutionalized population of 18-65 years $(n=4,486)$

\begin{tabular}{|c|c|c|c|c|c|c|c|c|}
\hline & $\begin{array}{l}\text { Physical } \\
\text { limitation }\end{array}$ & Happiness & $\begin{array}{l}\text { Perceived } \\
\text { mental health }\end{array}$ & $\begin{array}{l}\text { Perceived } \\
\text { physical health }\end{array}$ & Holidays & $\begin{array}{l}\text { Museum } \\
\text { visits }\end{array}$ & $\begin{array}{l}\text { Paid job } \\
\text { hours }\end{array}$ & $\begin{array}{l}\text { Contacts } \\
\text { friends }\end{array}$ \\
\hline Physical limitation & & -0.103 & -0.145 & -0.261 & -0.078 & 0.005 & -0.107 & -0.048 \\
\hline Duration of illness & 0.268 & -0.083 & -0.105 & -0.405 & & & & \\
\hline Gender (female) & 0.022 & & -0.100 & -0.064 & & & -0.324 & \\
\hline Age & 0.183 & & 0.096 & -0.021 & & & -0.269 & -0.176 \\
\hline Net household income & -0.047 & 0.120 & 0.078 & & 0.161 & & 0.189 & \\
\hline Level of education & -0.127 & & 0.006 & & 0.159 & 0.282 & 0.085 & \\
\hline
\end{tabular}

Source: Statistics Netherlands (POLS'01), SCP processing

${ }^{a}$ Nonsignificant $(p>0.05)$ relationships are not entered in the model and remain blank in the table

Table 7 Correlation coefficients ${ }^{\text {a }}$ between error terms of the outcome indicators of quality of life model 2 in the Dutch non-institutionalized population of $18-65$ years $(n=4,486)$

Happiness Perceived mental health Perceived physical health Holidays Museum visits Paid job hours

Perceived mental health 0.336

Perceived physical health

Holidays $\quad 0.047$

Museum visits

Paid job hours

0.046

$-0.173$

0.030

0.059

0.059

0.052

0.034

0.047

$-0.030$

Source: Statistics Netherlands (POLS'01), SCP processing

${ }^{a}$ Correlations adjusted for model variables. Only significant $(p<0.05)$ coefficients are shown

Secondly, there is a difference between objective participation, for example the number of paid hours' work performed during the week, and subjective participation, for example enjoying one's work. Various studies point to the importance of subjective indicators of social participation $[20,39]$. The perceived quality of work (factors such as control, esteem, promotion prospects), for example, has an effect on perceived health $[35,40]$. De Beer has shown that it is not so much the objective aspects of work, such as the number of hours worked per week, but the psychological aspects of work, such as atmosphere, daily routine and future expectations, which determine a person's satisfaction with their work [20].

Increasing the objective labour market participation rate does not appear to be enough to promote better well-being. The Flow Theory developed by Csikszentmihalyi [41] emphasises this: it is not what a person does but how they do it that is important for their sense of well-being. Freely interpreted, it is not the fact that someone participates but how they participate which determines their subjective well-being. Naturally, this only applies above a certain minimum level of participation in society. The added returns of more social contacts is limited above a certain minimum. Above this minimum it is the quality of the social contacts which matters, and not so much the quantity (at least this is the expectation, because the quality of social contacts was not measured). Ziersch et al. [36, 42] have shown that it is not so much the presence of 'social capital' as the 'relative perceived advantage' of that capital which impacts on perceived health. Cantor and Anderson [39] argue that lasting, useful participation has an impact on subjective well-being. Veenhoven [13] stresses the importance of structure and regularity, for example through work routine, for feelings of happiness. Seligman [43] stresses people's competencies as the most important determinant of happiness.

Based on these insights, we would recommend the inclusion of indicators for subjective participation alongside indicators for objective participation in explanatory models. This could be done by collecting data using Csikszentmihalyi's Experience Sampling Method or the more recent Day Reconstruction Method [44]. They have shown that this method can distinguish between the different influences of the performance of activities and the perception thereof on people's well-being.

\section{Conclusion}

The idea that subjective well-being is the outcome of a chain of impaired bodily functions, limited activities and restricted participation is rejected by this study. 
The length of illness and severity of physical limitations have a direct influence on objective participation, but the indicators for objective participation shows virtually no correlation with perceived health and happiness.

A policy recommendation based on this latter finding would be to regard objective participation and subjective well-being as separate policy outcomes. The assumption that a higher objective participation leads to better subjective well-being in persons with disabilities is contradicted by the empirical findings. If there is a correlation between these two aspects of quality of life, then it probably operates via the evaluation of the participation. Based on these findings, the commitment to making it possible for people with physical disabilities to participate in society will only lead to better subjective well-being for this group if they perceive that participation as valuable (i.e., enjoy it) and are able to realise longer-term personal goals as a result of it.

\section{References}

1. Office for Disability Issues, Social Development Canada. (2005). Advancing the inclusion of persons with disabilities 2005. Ottawa: Social Development Canada.

2. Klerk, M. de (2002). Report on the Disabled 2002. Haag: SCP.

3. World Health Organisation (2001). The international classification of functioning, disability and health-icf. Geneve: WHO.

4. Jette, A. M. (2006). Toward a common language for function, disability, and health. Physical Therapy, 86(5), 726-734.

5. Post, M., Witte, L. de, \& Schrijvers, A. J. P. (1999). Quality of life and the ICIDH: Towards an integrated conceptual model for rehabilitation outcomes research. Clinical Rehabilitation, 13, 5-15.

6. Ware, J. E., et al. (2002). How to score version 2 of SF-36 health survey. Lincoln: Quality Metric.

7. Cummins, R. A., Lau, A. L. D., \& Stokes, M. (2004). HRQOL and subjective well-being: Noncomplementry forms of outcome measurement. Expert Review of Pharmacoeconomics and Outcomes Research, 4(4), 413-420.

8. Cummins, R. A. (2000). Objective and subjective quality of life: An interactive model. Social Indicators Research, 52(1), $55-72$.

9. Veenhoven, R. (2000). The four qualities of life: Ordering concepts and measures of the good life'. Journal Of Happiness Studies, 1, 1-39.

10. Wellink, H. (2003). Een beetje meer draagkracht graag. Determinanten van de kwaliteit van leven van mensen met lichamelijke beperkingen. Utrecht: Universiteit Utrecht (doctoraalscriptie Algemene Sociale Wetenschappen).

11. Post, M. W., Van Dijk, A. J., Van Asbeck, F. W., \& Schrijvers, A. J. P. (1998). Life satisfaction of persons with spinal cord injury compared to a population group. Scandinavian Journal of Rehabilitation Medicine, 30(1), 23-30.

12. RIVM (2002). Volksgezondheid Toekomst Verkenning 2002. Bilthoven: RIVM.
13. Veenhoven, R. (2004). The greatest happiness principle. Happiness as a public policy aim. In P. A. Linley \& S. Joseph (Eds.), Positive psychology in practice, chapter 39. John Wiley: Hoboken, NJ.

14. Tate, D. G., Kalpakjian, C. Z., \& Forchheimer, M. B. (2002). Quality of life issues in individuals with spinal cord injury. Archives of Physical Medicine and Rehabilitation, 83(12 Suppl 2), S18-25.

15. Dijkers, M. P. (1999). Correlates of life satisfaction among persons with spinal cord injury. Archives of Physical Medicine and Rehabilitation, 80(8), 867-876.

16. Bent, N., Jones, A., Molloy, I., Chamberlain, M. A., \& Tennant, A. (2001). Factors determining participation in young adults with a physical disability: A pilot study. Clinical Rehabilitation, 15(5), 552-561.

17. Manns, P. J, \& Chad, K. E. (1999). Determining the relation between quality of life, handicap, fitness, and physical activity for persons with spinal cord injury. Archives of Physical Medicine and Rehabilitation, 80(12), 1566-1571.

18. Post, M. W., de Witte, L. P., van Asbeck, F. W., van Dijk, A. J., \& Schrijvers, A. J. P. (1998). Predictors of health status and life satisfaction in spinal cord injury. Archives of Physical Medicine and Rehabilitation, 79(4), 395-401.

19. Diener, E., \& Suh, E. (1997). Measuring quality of life: Economical, social and subjective indicators. Social Indicators Research, 40(1-2), 189-216.

20. Beer, P. T. de. (2001). Over werken in de postindustriële samenleving. Den Haag: SCP.

21. Elchardus, M., Derks, A., Glorieux, I., \& Pelleriaux, K. (1996). Voorspelbaar ongeluk: over letsels die werkloosheid nalaat bij mannen en hun kinderen. Brussels: VUB Press.

22. Boelhouwer J., \& Roes, Th. H. (2004). Monitoring the social state of the Netherlands: A model based approach to describing living conditions and quality of life. In W. Glatzer et al. (Eds.) Challenges for quality of life in the contemporary world. Dordrecht: Kluwer.

23. Jehoel-Gijsbers, G. (2004). Sociale uitsluiting in Nederland. Den Haag: SCP.

24. Sprangers, M. A. G., et al. (2000). Which chronic conditions are associated with better or poorer quality of life? Journal of Clinical Epidemiology, 53, 895-907.

25. Botterweck, A., et al. (2001). Plausibiliteit nieuwe metingen algemene gezondheid en leefstijlen 2001. Heerlen: CBS.

26. Ware, J. E., Kosinski, M., \& Keller, S. D. (1996). A 12-item short-form health survey. Medical Care, 34(3), 220-233.

27. Garratt, A., Schmidt, L., Mackintosh, A., \& Fitzpatrick, R. (2002). Quality of life measurement. BMJ, 324, 1417-1419.

28. Johnston, M. V., \& Miklos, C. S. (2002). Activity-related quality of life in rehabilitation and traumatic brain injury. Archives of Physical Medicine and Rehabilitation, 83(12 Suppl 2), S26-38.

29. Hays, R. D., Hahn, H., \& Marshall, G. (2002). Use of the SF36 and other health-related quality of life measures to assess persons with disabilities. Archives of Physical Medicine and Rehabilitation, 83(12 Suppl 2), S4-9.

30. Andresen, E. M., \& Meyers, A. R. (2000). Health-related quality of life outcomes measures. Archives of Physical Medicine and Rehabilitation, 81(12 Suppl 2), S30-45.

31. Mattson-Prince, J. (1997). A rational approach to long-term care: comparing the independent living model with agencybased care for persons with high spinal cord injuries. Spinal Cord, 35, 326-331.

32. Arbuckle, J. L., \& Wothke, W. (1999). Amos 4.0 User's Guide. Chicago: SmallWaters Corporation.

33. Kline, R. B. (1998). Principles and practice of structural equation modeling. NY: Guilford Press. 
34. Schafer, J. L. (1999). NORM: Multiple imputation of incomplete multivariate data under a normal model, version 2. http://www.stat.psu.edu/ jls/misoftwa.html.

35. Siegrist, J., \& Marmot, M. (2004). Health inequalities and the psychosocial environment-two scientific challenges. Social Science and Medicine, 58, 1463-1473.

36. Ziersch, A. M., Baum, F. E., Macdougall, C., \& Putland, C. (2005). Neighbourhood life and social capital: The implications for health. Social Science and Medicine, 60(1), 71-86.

37. Savelkoul, M. (2002). The influence of coping on social support and quality of life of people with rheumatic diseases. Maastricht: Universiteit Maastricht.

38. Gottlieb, A., Golander, H., Bar-Tal, Y., \& Gottlieb, D. (2001). The influence of social support and perceived control on handicap and quality of life after stroke. Aging, 13(1), 1115 .

39. Cantor N., \& Anderson C. A. (1999). Life task participation and well-being: The importance of taking part in daily life.
In D. Kahneman et al (Ed.), Well-being: The foundations of hedonic psychology. New York: SAGE.

40. Belkic, K. L., Landsbergis, P. A., Schnall, P. L., \& Baker, D. (2004). Is job strain a major source of cardiovascular disease risk? Scandinavian Journal of Work, Environment and Health, 30, 85-128.

41. Csikszentmihalyi, M. (1990). Flow: The psychology of optimal experience. New York: Harper Collins.

42. Ziersch, A. M. (2005). Health implications of access to social capital: Findings from an Australian study. Social Science and Medicine, 61(10), 2119-2131.

43. Seligman, M. (2004). Authentic happiness. New York: Free Press.

44. Kahneman, D., Krueger, A. B., Schkade, D. A., Schwarz, N., \& Stone, A. A. (2004). A survey method for characterizing daily life experience: The day reconstruction method. Science, 306, 1776-1780. 